\title{
Ladrões e Caçadores: Sobre um Carro Roubado em São Paulo'
}

\section{Thieves and Hunters: On a Stolen Car in São Paulo}

\section{Gabriel Feltran}

Universidade Federal de São Carlos. São Carlos, São Paulo, Brasil

\section{Deborah Fromm}

Universidade Estadual de Campinas, Campinas, São Paulo, Brasil

\section{RESUMO}

Trabalhos seminais como os de Knowles (2014) e de Tsing (2005) elevaram a tradição do estudo da trajetória de objetos a uma escala transnacional, e teoricamente inovaram ao focar não apenas nas jornadas como conectores fundamentais para a compreensão do mundo social, mas nos efeitos teóricos dessa operação metodológica. Para muito além da ideia de fluxos, assemblages e linhas de força descarnadas, as autoras propõem uma teoria imersa em situações empíricas concretas. Neste artigo, buscamos analisar as relações entre violência, mercados ilegais, desigualdades, seguro e proteção patrimonial, a partir da trajetória de um carro roubado, recuperado por uma das principais seguradoras do país.

Palavras-chave: Violência, Mercados ilegais, Desigualdades, Seguro, Proteção patrimonial.

\section{ABSTRACT}

Seminal works such as Knowles (2014) and Tsing (2011) elevated the tradition of studying the trajectory of objects towards a transnational scale, and theoretically innovated by focus in fundamental connectors for understanding the social world, button the theoretical

1 Agradecemos a Luana Motta, André de Pieri, Janaína Maldonado, Isabela Vianna, Gregório Zambon, Lucas Fernandes, Juliana Alcântara e Luiz Gustavo Pereira pela parceria na pesquisa que embasa essa reflexão. O projeto de pesquisa teve apoio da FAPESP nos marcos do CEPID CEM (2013/07616-7). 
effects produced by this methodological operation. Beyond the idea of flows, assemblage sand lines of force, the authors propose a theory embedded in concrete empirical situations. In this article, we propose to analyze the relationship between violence, illegal markets, inequality, insurance and social protection, based on the trajectory of a stolen car, recovered by one of the main insurers in the country.

Keywords: Violence, Illegal markets, Inequality, Insurance, Social protection.

\section{INTRODUÇÃO}

Estudar a vida social de objetos é uma tradição metodológica já consolidada nas Ciências Sociais (APPADURAI, 1986, 1997; FREIRE-MEDEIROS; MENEZES, 2016; HENARE; HOLBRAAD; WASTELL, 2006; KNOWLES, 2014; KOPYTOFF, 2014; LATOUR, 2005; MILLER, 2001, 2010; MINTZ, 2003). Mas não apenas nelas: "seguir o dinheiro", por exemplo, é um dos métodos mais consolidados também nas investigações policiais dedicadas a compreender a operação de redes complexas do que se chama de "crime organizado"2. Recentemente, trabalhos seminais como os de Knowles (2014) e de Tsing (2005) elevaram essa tradição a uma escala transnacional, e teoricamente inovaram ao focar não apenas nas trajetórias ou jornadas como conectores fundamentais para a compreensão de um mundo social globalizado, mas nos efeitos teóricos da operação metodológica por elas empreendida. Para muito além da ideia de fluxos, assemblages e linhas de força descarnadas, as autoras propõem uma teoria imersa em situações empíricas concretas. E, portanto, muito plurais.

No debate sobre as mobilidades (FREIRE-MEDEIROS; TELLES; ALLIS, 2018; MARTINS JUNIOR, 2015; URRY, 2002, 2004, 2010), a contribuição de Amit e Knowles (2017) propõe a noção de "tacking" como um frame produtivo para assumir a importância da improvisação cotidiana de atores, dominantes ou subalternos, na construção de suas próprias possibilidades de atuação no tecido social. Essa improvisação teria elementos como inventiveness, timing, the unexpected e seria uma forma recorrente, embora pouco discutida, pela qual os sujeitos contemporâneos navegam por suas vidas cotidianas ${ }^{3}$. Oportunidades de sobrevivência

2 Uma linha de estudos etnográficos sobre o mundo do crime, no Brasil, se construiu em oposição à noção normativa e jurídica de crime organizado (BIONDI, 2018; FELTRAN, 2016; HIRATA, 2010; TELLES, 2010).

3 Embora Georg Simmel não esteja no quadro fundamental de referências das autoras, a abordagem proposta por elas pode ser relacionada diretamente ao que o Simmel teoriza (SIMMEL, 2010), bem como aos resultados dessa 
e negócio, geração de renda, mobilidade e produção de formas de vida seriam, em boa medida, também resultado de improvisação situacional frente a barreiras e problemas cotidianos, muito diversos, porque o mundo tem mudado rapidamente.

A noção de "tacking" é ainda mais útil quando se trata de estudar circuitos criminalizados, como fazemos neste artigo. Ao contrário de outros mercados, nos quais fazer propaganda e marketing são fundamentais, no mundo ilegal manter-se operando em sigilo é "a alma do negócio". Como a repressão é sempre potencial, é preciso também diversificar as rotas, esconder os armazéns, modificar os caminhos e trocar as senhas (mas também os chips e aparelhos de telefone celular, os endereços e as roupas, cabelo e visual, e às vezes a própria fisionomia). As circunstâncias mudam ainda mais rápido, nos mercados ilegais, e toda e qualquer ação pode estar sendo vigiada pela polícia, ou por rivais, inimigos.

Além disso, na esfera criminal muitas vezes não há qualquer estabilidade garantida por uma burocracia, ou informações confiáveis disponíveis aos operadores. Por isso mesmo, estimula-se a organização horizontal. As facções criminais, máfias, cartéis e gangues são uma forma de produzir ambientes internos de confiança, funcionando como instituições sob lógica de honra, estamentais. Seja com que intensidade for, as habilidades de inventividade, timing e de lidar com o inesperado, como Amit e Knowles (2017) propõem, estão na base da operação dos estímulos e dos entraves à circulação global contemporânea de mercadorias, serviços, pessoas.

Como a instabilidade se amplia no mundo contemporâneo - vide os efeitos da expansão do Covid-19 em 2020 - as circunstâncias e a definição das situações é, quase sempre, contingente. A capacidade de improvisar e adaptar-se é uma das virtudes mais prezadas pelas instituições e mercado de trabalho contemporâneos; não é diferente nos mercados (i)legais. Metodologicamente, considerar o tacking cotidiano como estruturante da ação dos operadores é mais realista do que partir de quaisquer teorias racionalistas ou estruturalistas. Ao mesmo tempo, os efeitos dessas improvisações produzem estruturas bastante rígidas de desigualdades, e muita especificidade na disposição da violência (FELTRAN, 2012).

Os atores improvisam, mas sempre muito constrangidos; ao improvisarem, criam soluções e inovações, rompem padrões, mas não o fazem livremente. Um olhar de longa duração vê a reprodução do mesmo conflito urbano capitalista já muito conhecido das teorias clássicas, mas agora sob uma pluralidade enorme de formas de vida, e de ordens de governo do urbano, contemporâneas. Atores movem-se e produzem suas histórias desiguais, mas dentro das balizas plausíveis, possíveis, oferecidas por cada momento histórico, cada espaço, ou seja, por cada si-

produção, tanto no clássico de Goffman (2016), quanto depois em (CEFAÏ; GARDELLA, 2011). 
tuação, entendida como parâmetro situado de estruturação social. A tendência dessa construção, sem dúvida, aponta para um mundo social crescentemente desigual, e crescentemente violento.

Da mesma forma, é longa a tradição de estudos sociológicos amparados em histórias de vida (ARENDT, 1994; BERTAUX, 1981; FOUCAULT; BARBIN, 1980; LEWIS, 1961) e trajetórias (BOURDIEU, 1986, 2004; CABANES, 2004; TELLES, 2010). O encontro situacional em pesquisa etnográfica também rendeu narrativas profícuas na antropologia, sobretudo as que colocam em relação as histórias de vida de pesquisadores e de seus interlocutores (DAS 2006; FELTRAN 2017). Nesse sentido, autobiografias e biografias tornam-se geradoras da unidade analítica a ser trabalhada nesse artigo - as journeys dos carros roubados ou furtados, bem como de seus proprietários e ladrões (BOURDIEU, 1986, 2004, 2011).

\section{LADRÕES}

Ainda antes do almoço, mas agora na Zona Oeste da capital, João, um profissional de 35 anos, casado, teve seu Hyundai HB20, 1.0, 2014 furtado, depois de estacionar próximo à movimentada estação da CPTM de Presidente Altino, em Osasco. Ladrões experientes sabem que, uma vez que o dono do carro tenha entrado no transporte público, haverá tranquilidade e tempo hábil para praticar o furto. João vive no Parque Continental, bairro residencial, vizinho à estação. Não tem filhos, trabalha numa multinacional do agronegócio, na área de "novos negócios". Formado em agronomia, vindo de família de classe média branca de uma pequena cidade interior, João sempre demonstrou entender sua posição na estratificação social, e suas responsabilidades com os pais, pouco escolarizados, que juntos ganham dois salários mínimos mensais. João - rapaz loiro, olhos claros, alto, bem empregado - sabe que está com ele a responsabilidade pela manutenção do bem estar da família ampliada.

Aos 17 anos mudou-se para a casa de parentes em São Paulo, para fazer cursinho privado na cidade grande. Com o apoio de um tio, que tinha uma situação melhor de vida, conseguiu se dedicar e foi aprovado em uma universidade pública, no interior. João dosou as festas universitárias e os estudos com equilíbrio, e se formou aos 22. Postulou para estagiário na Chemical Agro por intermédio de um professor. Desde então atua na empresa, tendo tido duas promoções: uma delas o levou a viver por um ano no sul do país, a outra o trouxe de volta a São Paulo.

Naquela terça feira, João tinha respondido aos seus e-mails e trabalhado de casa, por telefone, logo cedo. Tinha agora dois clientes para visitar na Zona Norte da cidade, o primeiro 
ainda antes do almoço, o segundo logo depois. Pensou que, se essa segunda visita atrasasse, ele teria que esperar o final do seu rodízio ${ }^{4}$, às $20 \mathrm{~h}$, para voltar para casa. São Paulo tem um sistema de rodízio de veículos em horários de pico, das $7 \mathrm{~h}-10 \mathrm{~h}$ da manhã, das $17 \mathrm{~h}-20 \mathrm{~h}$ da noite. As placas com final 4, como a de João, não podem circular às terças, nesses horários. Por isso, João preferiu dirigir até a estação de trem. O caminho até a zona norte seria mais demorado, menos confortável, mas evitaria o trânsito da volta. Tudo bem.

Grandão vestia bermuda, chinelos, agasalho, boné de aba reta e capuz nesse dia. É um homem corpulento, também com 35 anos, negro, acima do peso, cavanhaque bem cortado. $\mathrm{Na}$ quebrada é conhecido como boa vida, sempre sorridente em seu GM Omega, 1998, prateado, rebaixado, rodas de liga leve, com adesivos de equipes de som. Sua família é conhecida no bairro pelo envolvimento com o mundo do crime. Sua mãe toca uma pequena venda informal, no fundo da casa, que conheceremos mais tarde. Nesse dia, Grandão também saiu cedo para "trabalhar", como ele diz, e vinha acompanhado de um parceiro, moleque novo, Wellington. Os dois vieram do extremo Oeste da Região Metropolitana, Jandira, de GM Corsa. Grandão nunca usa seu Omega quando vai trabalhar. O parceiro Wellington era novato, trazido para assistir a ação, aprender como se faz, e levar o carro até o local de descanso.

Grandão é bem mais experiente que Wellington, e muito mais rápido; Grandão dá uma volta rápida em torno do HB20 que visava, indo e voltando pela rua, certificando-se de que não está sendo observado. Sente-se seguro, vai até o veículo e, em não mais de três segundos, abre a porta do carro com uma chave micha. Abre a porta do motorista e senta-se no banco do motorista, com uma perna para fora. Nem mesmo fecha porta, e já destrava o capô. O HB20 pisca, começa a buzinar, mas por pouquíssimo tempo. Grandão abre o capô pela frente, desliga a buzina em mais três segundos. Faz-se silêncio. Então ele troca o módulo de injeção do veículo, também muito rapidamente. Muita prática, vê-se que ele faz isso seguidamente. Grandão deixa a porta aberta, e chama Wellington, que dá partida e segue o GM Corsa dirigindo o HB20 furtado. A ação não durou mais do que dois minutos. Em entrevista, Grandão nos conta que "puxa" de 8 a 10 carros por semana, em geral um de manhã, outro de tarde, nos dias úteis. Fala com a sensação de que furtar é uma tarefa simples, conta como se faz com carros keyless: "quanto mais tecnologia, é mais fácil pra gente".

João não se desespera quando retorna do metrô às $15 \mathrm{~h}$, um pouco antes do planejado, e não encontra seu HB20 estacionado. Depois de segundos, parado na calçada, pensando se tinha

4 Em São Paulo, na intenção de diminuir trânsito e poluição, desde os anos 1990 é feito um rodízio de veículos pelo número da placa. Na região delimitada como centro expandido, limita-se a circulação de dois finais de placa em um determinado dia da semana. Dessa forma, em horários de pico, retira-se $20 \%$ da frota da circulação. 
mesmo parado ali, disfarça e pega o celular. Encosta numa árvore, sem se preocupar em sujar a camisa branca bem passada que vestia, por dentro da calça social azul, sapatos pretos. João tem seguro, está ligando para a Alvorada, sua Seguradora, e é atendido prontamente. Explica a situação, a atendente ${ }^{5}$ pergunta se ele está bem, se não houve violência, ele explica que não. Ela informa que João pode fazer o Boletim de Ocorrência online, não precisa ir para a Delegacia. Com o B.O. em mãos, ele poderia enviar o documento diretamente para a seguradora, ou para seu corretor de seguros, e o caso seria avaliado rapidamente. Normalmente, a indenização não demoraria. Ela envia por SMS um link com o passo a passo, perguntando ainda se João quer um táxi para voltar para casa. A apólice cobre esses serviços, ela relembra.

Enquanto espera para ver se o carro é recuperado, ou se deverá comprar outro, João poderá usar um carro reserva por quatro dias. Ótimo. João fica satisfeito com o atendimento, dá nota 10 ao final da ligação. O furto não lhe estressa tanto, é encarado como um contratempo. João desmarca uma conversa por telefone que teria no final da tarde com o chefe, conta a história rapidamente, diz que vai ter que encaminhar essas coisas. Vida na metrópole tem disso, sem problema. Pelo celular, ele resolve o que tem que resolver em mais 15 minutos, já sentado em uma lanchonete tomando uma Coca-Cola, comendo um misto quente. Mais cinco minutos, e recebe uma ligação da Polícia Civil para confirmar a veracidade do B.O. Só então ele liga para sua noiva, Marcella, que faz perguntas parecidas com as da Seguradora, mas com mais intimidade.

João tem projeto de se casar e ter filhos com Marcella, economista formada pela mesma universidade pública em que ele estudou, filha de pequenos empresários do ramo de sorvetes, também do interior. O casal pensa em voltar para o interior e assumir os negócios da família. Mas isso vai depender das oportunidades de João. Ele sente-se, ainda, começando sua vida profissional e vislumbra crescimento; teve um convite para atuar no mercado financeiro. Estudou a proposta, mas seguiu na Chemical Agro, que lhe dava mais segurança. Quem sabe logo pode deixar de viver com o tio, e mudar-se para um bairro mais tranquilo quando se casar e as crianças vierem. "Que vacilo parar o carro perto da estação", ele pensa. "Tem uma favela logo ali do lado..." "Pois é," Marcella replica, "mas na verdade poderia ter sido pior, por isso mesmo".

Eles concordam, enquanto conversam, que foi uma sorte não terem sido vítimas de um roubo violento. Graças a Deus, tudo está bem. O HB20 tinha seguro. “Acaba que vamos receber até um pouco mais do que ele valia no mercado", diz Marcella. Tudo bem, João pega o táxi de

5 A atendente da Alvorada Seguros se chama Bianca, 18, moradora da favela de Presidente Altino, negra, com ensino médio concluído há dois anos. Ela está guardando dinheiro para sair com sua filha da casa dos seus pais. A mãe está cuidando da pequena Luiza, o pai aparece de vez em quando, tem 21 anos, paga uma pensão. Bianca prefere que ele não veja a menina, está "envolvido com drogas", como ela diz. 
volta para casa, pensando no próximo carro que vai comprar, com o dinheiro da indenização. Grandão e Wellington também voltam para casa, depois de deixarem o HB20 estacionado em uma rua mais afastada de Osasco. Wellington estaciona o veículo e anda dois quarteirões, em uma esquina não muito movimentada, esperando que Grandão passe para levá-lo. Metade da missão daquele dia já estava cumprida.

João e Grandão têm a mesma idade, vivem na mesma zona Oeste das periferias da maior metrópole da América do Sul, mas jamais se encontraram pessoalmente. João, como a grande maioria dos que desconhecem o mundo do crime, acha que seu HB20 foi levado para a garagem de quem o subtraiu. Não sabe, como Grandão e Wellington, que o mercado de veículos é altamente especializado, com divisão de tarefas notável, e que seu carro rapidamente sairá da mão dos que o furtaram.

João foi furtado, não roubado. Há uma diferença determinante entre roubo e furto: o emprego de violência. Violência, nesse artigo e na tradição de estudos que o embasa, tem um sentido descritivo preciso; violência é o uso da força, ou de ameaça de usar a força que provoque efeito similar ao seu emprego efetivo (MISSE, 2006). Apontar uma arma e dizer para a pessoa entregar o carro é ainda mais persuasivo do que retirá-la à força de dentro dele. Nos furtos, ao contrário, a subtração do veículo se faz sem ameaças, sem armas e sem a presença do condutor. Nos roubos, ladrões e condutores interagem face a face, há sempre ameaças por parte do ladrão, que normalmente, mas não sempre em São Paulo, porta uma arma de fogo leve.

A tipificação de roubos e furtos que utilizamos aqui é parecida com a do Código Penal brasileiro. No entanto, é preciso ir muito além dele para que possamos entender as diferentes composições dos circuitos de roubo, e dos circuitos de furto, para o mercado ilegal de veículos em São Paulo. Essas diferenças partem das técnicas empregadas e do perfil dos ladrões, mas condicionam também as diferentes jornadas posteriores dos carros subtraídos. O furto de carros é, como veremos, "limpo". É o ponto de chegada do processo de profissionalização de ladrões e dos mercados ilegais de veículos. Quase sempre, entretanto, as trajetórias desses ladrões se iniciam no circuito de roubos violentos, muito mais perigosos para as vítimas e, sobretudo, para os ladrões. 


\section{CAÇADORES}

Vistos pela ótica do setor de seguros, o fenômeno do roubo e do furto de carros, para além de um "problema de segurança", passa a estar inserido no que autores influentes têm chamado de um processo de "economization of uncertainty" (O'MALLEY, 2004), concebido como mecanismo central de reprodução do capitalismo contemporâneo:

When uncertainty is standardized, homogenized and made calculable, it can be given a price and it can be bought and sold. Not only has it been economized, it has been made into essential commodity of current capitalism (LEHTONEN; VAN HOYWEGHEN, 2014, p. 1, grifo nosso).

De um lado, as apólices de seguro buscam minimizar e domesticar as incertezas tanto para o segurado, quanto para a seguradora. De outro lado, a incerteza, que seria uma ameaça, é convertida em uma oportunidade de bons negócios e lucros futuros. "Insurance should be considered as an uncertain business" (ERICSON; DOYLE, 2004, apud LEHTONEN; VAN HOYWEGHEN, 2014). "Insurance is also and always about proliferating and taming uncertainty." (LEHTONEN; VAN HOYWEGHEN, 2014).

Este artigo aborda as respostas do mercado segurador ao roubo de automóveis em São Paulo. Respostas, estas, pautadas pela tentativa de reparação econômica dos clientes frente aos danos gerados pelos eventos ilegais. As respostas da Alvorada Seguros serão nosso ponto de partida empírico. A companhia deve reparar os prejuízos econômicos das partes lesadas e, ao ser acionada por João, proprietário do HB20 furtado por Grandão, investiga o caso. Não tendo comprovado fraude, a Alvorada se responsabiliza pelo pagamento da indenização, ou pela recuperação e devolução do veículo para o segurado, caso este esteja em perfeitas condições.

Nosso argumento aqui diz respeito aos imbricamentos do legal-ilegal, a partir da constatação da produtividade social e mercantil do roubo de carros. Demonstramos como, de modo atrelado à "Robauto", como é reconhecida entre operadores a indústria de carros roubados de São Paulo, e graças à mediação do seguro, desenvolve-se uma série de outras atividades e circuitos econômicos altamente lucrativos, tais como o rastreamento e recuperação de veículos, as tecnologias de segurança e monitoramento e, no limite, a amplificação do faturamento da indústria automobilística.

Ao mesmo tempo em que fomenta mercados, a mediação dos seguros no mercado veicular produz um esquema de racionalidade que conecta proteção patrimonial e acumulação de recursos, dimensões articuladas de um mesmo negócio, concebido como passível apenas de 
regulação por uma companhia privada. Assim, proteção e seguro, dimensões fundamentais da própria consolidação da racionalidade previdenciária do Estado de Bem Estar, que estiveram na base da construção da própria ideia de direitos e de mundo público, durante o século XX, passam agora a ser concebidas como centralmente afeitas aos mercados, alavancando sua acumulação.

O seguro pensado como segurança desloca, ainda, o problema da punição aos ladrões, para uma racionalidade pragmática de reparação. A segurança proposta pela seguradora, ao contrário daquela que seria função de polícia, não se preocupa em perseguir ou punir. Não há reação moral ao roubo. O modelo de justiça posto em marcha pela Alvorada não emula, tampouco, o sistema jurídico estatal (EWALD, 1986, 1991). Independente do responsável pelo dano, se não há fraude, a indenização será paga. A reparação é econômica, e é possível precificar riscos, indenizações, bens e sujeitos (ZELIZER, 2017).

A racionalidade das seguradoras é direta: elas compram o risco e vendem a garantia de proteção, caso o infortúnio aconteça. Se não tivesse seguro, talvez João se desesperasse ao constatar o furto. Tendo, por outro lado, ficou tranquilo e, conversando com sua esposa, constatou que ter tido o carro roubado tinha sido até um bom negócio; os valores das indenizações praticadas pelas seguradoras costumam ser maiores do que os preços médios praticados no mercado de carros usados.

Seu Cláudio não tinha seguro. Mas quando João percebeu que seu HB20 2014 fora furtado, suspirou aliviado ao lembrar que havia renovado a apólice de seu seguro poucas semanas antes. Foi justamente o risco de ter o seu carro roubado, ou de sofrer um acidente de trânsito, o que sempre o motivou a manter em dia o pagamento do prêmio para a Alvorada Seguros. Quando não encontrou mais o HB20 na rua, e viu que o risco tinha se tornado realidade, João sentiu que sua postura preventiva havia valido à pena. A vida em grandes centros urbanos tem infortúnios, é bom estar preparado para eles ${ }^{6}$.

Vimos que a primeira medida de João, ao constatar o furto, e ainda de pé frente à vaga que havia estacionado, foi entrar em contato com a Alvorada Seguros, pelo Call Center da companhia. Uma atendente direcionou rapidamente o caso para a Central de Rastreamento e Monitoramento da seguradora, localizada em São Paulo, via e-mail. Esse setor da empresa,

6 Diferentemente de diversos países europeus, o seguro de automóvel não é obrigatório no Brasil. Proprietários de veículos apenas devem pagar, anualmente, o chamado DPVAT (a sigla significa Danos Pessoais por Veículos Automotores Terrestres), conhecido como "seguro obrigatório", voltado apenas para a indenização de vítimas de acidentes de trânsito, independente do responsável. Danos aos veículos ou ao patrimônio de terceiros não estão cobertos; trata-se de um seguro social administrado por um consórcio entre seguradoras privadas. 
uma das líderes no ramo de automóveis no Brasil, é responsável pelas buscas e recuperação de veículos roubados e furtados, assegurados pela companhia. O setor trabalha tanto com veículos que possuem dispositivo de rastreamento instalado, quanto com os que não possuem. No Brasil, e principalmente em São Paulo, o roubo de carros é uma preocupação central das seguradoras, que têm investido recursos e desenvolvido tecnologias para o rastreamento e monitoramento das propriedades de seus clientes, mas também deles mesmos.

O setor segurador estima que oito em cada dez veículos roubados ou furtados em São Paulo tenham cobertura de seguro. Ladrões visam carros mais novos, com poucos anos de uso. Apenas o grupo segurador Alvorada tem, em média, 100 sinistros de roubo ou furto de carros por dia, no Brasil. Mais de 12 mil carros das três marcas que compõem esse grupo de seguros desaparecem, anualmente. A média de recuperação de carros roubados e furtados pelo grupo é de $50 \%$, e pode aumentar para $90 \%$ se os carros tiverem um dispositivo de rastreamento instalado pela empresa. O grupo segurador Alvorada possui 5,5 milhões de carros segurados no Brasil, dos quais 300 mil possuem rastreadores instalados. O HB20 de João era um destes, porque o modelo é muito visado. Em 2017, estimava-se que a cada 69 Hyundai HB20 segurados, um é roubado/furtado no país ${ }^{7}$. A média geral das seguradoras é de 100 veículos segurados para cada roubo ou furto.

Na Central de Monitoramento da sede da Alvorada Seguros, uma equipe composta por aproximadamente 20 técnicos, sentados com computadores individuais em uma sala ampla, todos direcionados para uma TV de plasma pendurada na parede, consegue visualizar os sinistros e as respectivas cidades e estados em que ocorrem, em tempo real. Os sinistros mais recentes aparecem em vermelho, os mais antigos em amarelo e os que acabaram de ser solucionados, em verde.

Após receberem o e-mail de Bianca, os dados do HB20 2014 de João (placa, cor, chassi e a rua onde ocorreu o furto) foram imediatamente compartilhados pela equipe da Central com seus motoqueiros, através de um grupo de WhatsApp. Os motoqueiros que estavam mais perto do local do furto, na Estação da CPTM de Presidente Altino, em Osasco, poderiam dar início às buscas pelo veículo. O procedimento é sempre esse. Nas ruas da Região Metropolitana de São Paulo, a Alvorada conta com 35 pronta-respostas, rapazes que buscam os carros com sinal de rastreador; e 25 caçadores, os que recuperam carros sem rastreador, por possuírem mais experiência na atividade. Geralmente, os caçadores e pronta-respostas se dividem em duplas, trabalham com motos deles mesmos, e ficam responsáveis por determinada região da cidade.

7 Segundo dados da SUSEP, em 2017, haviam 131.919 unidades e 1911 foram roubadas/furtadas. 
Douglas é, há um ano, um desses pronta-respostas da Alvorada Seguros. Através de seu smartphone, pelo grupo de Whatsapp da equipe, o motoqueiro viu que o furto do HB20 de João ocorreu na sua região de atuação. Por isso, foi acionado pela central. Douglas faz as buscas pelas periferias da zona Oeste da Região Metropolitana de São Paulo, onde nasceu e mora até hoje. Antes, trabalhava como motoboy, fazendo entregas por toda a cidade. Em entrevista, Douglas disse preferir seu atual serviço, pois considera mais tranquilo e consegue receber um pouco mais. Em média, recuperando veículos ele consegue ganhar 3,8 salários mínimos por mês. É trabalhador autônomo e presta o serviço para a seguradora através de contratos temporários, renováveis a cada três meses. Não possui vínculo empregatício com a empresa e, portanto, não tem direito a férias, $13^{\circ}$ salário ou outros benefícios.

Sua rotina é acordar bem cedo e sair de casa às 6 h da manhã para fazer uma varredura pela região. Este procedimento é chamado de "romeu" pela equipe. Diz preferir sair cedo, para que circule antes de seus vizinhos, ladrões de carros, acordarem. De manhã, ele roda avenidas e vielas onde sabe que os ladrões costumam deixar "descansando" os carros que roubaram ou furtaram. Algumas características o fazem considerar o veículo como "suspeito": modelo de carro fora do perfil socioeconômico do bairro (ele deu o exemplo de um BMW de luxo na favela); painel estourado (os ladrões costumam pendurar a sacolinha do lixo ao lado do volante para esconder que o painel está estourado, isso é um indício para os recuperadores); airbag estourado; carro sujo, mal estacionado ou sem rodas. Quaisquer desses indícios levam Douglas a checar a placa do carro num aplicativo do governo federal, chamado SINESP Cidadão. Trata-se de um aplicativo com acesso público e gratuito que indica a qualquer cidadão, por simples consulta de placas, que veículos foram roubados, furtados ou clonados. A partir de seu próprio celular, portanto, Douglas consegue saber se o carro está "cantando", como ele diz.

Assim que acionado para um caso, o pronta-resposta recebe US\$ 6,5 para cobrir os custos com combustível. Douglas roda aproximadamente $70 \mathrm{~km}$ por dia, o que lhe rende um custo com combustível de quase $0,5 \mathrm{SM}^{9}$ por mês, pago integralmente pela seguradora. Quando recupera um carro, recebe 0,18 SM (com rastreador) e 0, $26 \mathrm{SM}$ (sem rastreador). Sua meta é sempre recuperar, no mínimo, 15 carros por mês. Após a varredura matinal, Douglas costuma voltar para almoçar em casa e, de tarde, sai apenas se for requisitado pela central para encontrar

8 Termo usado pela equipe para se referir aos carros que foram roubados/furtados e a polícia já tem conhecimento. Nesses casos, em que o Boletim de Ocorrência já foi feito, através da placa do veículo o aplicativo do governo federal indica que o carro foi roubado/furtado e está sendo procurado.

9 Salário Mínimo. 
algum carro que o rastreador indica estar nas proximidades. Foi assim com o HB20 de João.

Douglas é vizinho de Grandão, cresceram no mesmo bairro na periferia de Carapicuíba, periferia Oeste da Região Metropolitana, vizinha a Osasco. Eram colegas quando crianças, mas na vida adulta os caminhos que escolheram os acabaram distanciando. Enquanto Douglas recupera carros para a seguradora, Grandão furta veículos para abastecer desmanches. É em torno da atividade ilegal de Grandão que o mercado securitário, do qual o sustento da família de Douglas depende, se articula e se expande para suprir a demanda por proteção. Como um dos coordenadores da central da Alvorada Seguros sintetiza: "precisa do roubo para depois todo mundo começar a trabalhar". Contraditoriamente ou não, trabalhos formais na Central de Monitoramento, ou precários como o de Douglas, são gerados a partir do roubo de carro.

Douglas encontrou o HB20 de João que foi deixado "descansando" por Grandão, em uma rua pouco movimentada de Osasco. Ao localizar o carro, Douglas preenche um formulário sobre as condições do veículo quando encontrado, através de um tablet concedido pela seguradora. Em seguida, anexa fotos do veículo para comprovar as informações inseridas. Depois de ter sido comunicada do paradeiro do automóvel, por Douglas, a Central entra em contato com a polícia, o guincho e um chaveiro. Os dois últimos devem ir até o local para garantir o deslocamento do veículo para a delegacia de Polícia Civil mais próxima, ou responsável por aquele distrito policial. Douglas não pode se afastar do veículo até a polícia chegar, o que pode levar horas. Em geral, ele opta por permanecer em um local a partir do qual consiga ver o veículo, mas que não possa ser visto. Isso porque, eventualmente, o ladrão pode retornar para buscar o carro e Douglas quer evitar conflitos.

O HB20 de João possuía rastreador, mas o equipamento estava instalado em lugar previsível, no compartimento da luz interna do veículo, e Grandão o havia localizado rapidamente, durante o furto. Retirado o rastreador, Grandão estranhou quando não encontrou o carro onde o havia deixado, em Osasco. Sempre pode haver mais de um device, é certo, não há como os ladrões terem certeza de que, mesmo tendo descoberto um rastreador, ele seja o único aparelho instalado. Mas aquilo pareceu suspeito, na visão de Grandão, que conhecia Douglas desde criança.

Em conversa com outros parceiros do seu bairro, que também puxam carros em Osasco, Grandão demonstrou sua insatisfação com as recuperações feitas por Douglas. Era prejuízo para eles. Grandão desconfiava que Douglas, para além de seu trabalho de rotina, poderia estar vigiando as atividades dos ladrões, vendo quando saíam com o GM Corsa, para roubar, e vigiando em seguida os locais em que deixam os carros roubados, com mais frequência. Isso não estava certo. Grandão, como sabemos, vem de uma família com caminhada extensa no mundo 
do crime da região. A quebrada é PCC, como a grande maioria das favelas e periferias do estado de São Paulo. Grandão conhece "os disciplinas” dali. Chamou uma conversa com eles.

Estes foram até a casa de Douglas, tocaram a campainha e, com todo o respeito, o questionaram sobre os carros que ele vinha recuperando e, em especial, sobre o HB20 branco. Segundo Douglas, ele disse para os colegas que o carro estava com o rastreador funcionando, e que a empresa iria recuperar e acionar a polícia de todo jeito. Os rapazes retrucaram que Grandão havia retirado o rastreador, mas Douglas disse que havia mais de um. Ficou "o dito pelo não dito", e "os disciplinas" não tinham como provar que Douglas estava errado, condição necessária para quaisquer cobranças mais incisivas por parte do PCC. O recado estava passado, entretanto. Douglas sabia que estavam de olho nele. E sabia também que havia mentido, porque na realidade ele havia conseguido encontrar o veículo por já conhecer os locais usados por Grandão para deixar o carro "descansando", ou por outros ladrões para fazer desmontagem precária, na própria rua. $\mathrm{O}$ universo criminal tem nas facções, como sabemos, instâncias de regulação dos mercados criminais e, mesmo, dos mercados de proteção a eles associados.

De um lado, operações policiais no território não são boas para os negócios criminais, podem render prisões ou custos mais elevados com subornos. Pode ser melhor que alguém da própria comunidade, como Douglas, recupere alguns veículos para evitar a vinda da polícia. De outro lado, o fato de seus colegas aparecerem em sua porta revela tensões entre as atividades dos vizinhos de bairro. Douglas precisa trabalhar e seu trabalho é honesto, todos reconhecem, mas ele também é alguém "da comunidade" e, portanto, não deveria agir contra os interesses e preceitos de seus pares, daqueles que cresceram com ele.

Em outras palavras, existe uma linha tênue entre Douglas ser considerado, na comunidade, um trabalhador que age corretamente e, como resultado de seu ofício, inclusive evita conflitos com a polícia; ou ser considerado um "cagoeta", um delator, um traidor, que contribui com informações para policiais e seguradoras encontrarem carros roubados, dificultando os negócios de seus vizinhos e amigos de infância. Nessa linha tênue decide-se não apenas a vida de Douglas, mas sobretudo os limites dos mercados. No primeiro caso, ele será respeitado pelo mundo do crime local, e poderá seguir realizando seu trabalho; no segundo caso, será cobrado radicalmente e o serviço de "pronta-resposta", ao longo do tempo, tenderá a ser extinto.

Essa linha tênue de conflito produz as condições necessárias para que haja negociação entre as partes, e regulação mútua tanto das atividades de proteção, quanto das atividades ilegais (WHYTE, 1943). Se essa negociação de fato se produzir entre os agentes, e é a performance de cada um deles o que determina essa possibilidade, o mercado de veículos roubados, bem como as atividades de proteção, podem seguir coexistindo no bairro. A Alvorada continuará 
recuperando veículos suficientes, e Grandão continuará a ter furtos bem sucedidos suficientes. Ninguém maximizará seus lucros, mas ninguém ficará sem dinheiro. Se a negociação não vingar, seguramente pode eclodir violência entre as partes, e a mais forte vencerá.

A conversa amistosa entre Douglas e os “disciplinas" daquela quebrada, em Carapicuíba, inscreve nos cotidianos do bairro diferentes linhas do conflito urbano. Em uma escala, são os ganhos do mercado ilegal de veículos, entre seguradoras e empresários criminais, o que está em jogo. Em outra escala, são os interesses de Douglas e de Grandão. Interessa à Alvorada que Douglas recupere todos os carros segurados, e interessa a Grandão, como aos empresários de desmanches, que Douglas não recupere nenhum. Se Douglas ganha, ganha a Alvorada também. Se Grandão ganha, ganham também os empresários de desmanches.

Cada um trabalha dentro de seus interesses, e com suas instâncias de regulação de mercado. Se a Alvorada vai recorrer aos atores de mediação estatal para tentar garantir e potencializar seus lucros, aqui Grandão recorre ao ator central de regulação do mundo do crime em São Paulo, o Primeiro Comando da Capital (FELTRAN, 2018). A negociação na porta da casa de Douglas inscreve, portanto, também negociação entre diferentes regimes normativos que podem, de um lado, favorecer a coexistência dos mercados legal e ilegal, e os ganhos compartilhados entre ambos. De outro lado, o fracasso da negociação entre Douglas e Grandão pode redundar em desacordo explícito, o que poderia levar os atores, imediatamente, a recorrerem à violência. É assim que se produz a "violência urbana", e a plausibilidade dos homicídios nas periferias brasileiras.

Douglas teria a polícia para acionar, em caso de recrudescimento de seu conflito com "os disciplinas" da quebrada, e com Grandão. A violência legítima do Estado é voltada, normativamente, para ordenar as ilegalidades; mas se recorresse à polícia, Douglas teria sua posição na comunidade ameaçada, e possivelmente, inviabilizada. Grandão tem ao seu lado a violência do mundo do crime, legítima na comunidade desde que aplicada na direção considerada "correta", sem opressão. Essa violência, por isso, é regulada pelo arbítrio de uma fraternidade secreta, a forma extremamente bem sucedida em que o PCC passou a atuar em São Paulo, a partir dos anos 2000. Disputas de mercado se convertem em disputas por legitimidade no uso da força, portanto em disputas políticas.

No caso de Grandão e Douglas, houve um acordo tácito. Os espaços de cada um passaram a ser mais respeitados, evitando conflitos. Apenas entre janeiro e maio de 2018, quando a pesquisa se desenvolveu com mais intensidade nas seguradoras, foram recuperados pela equipe da Alvorada Seguros nada menos de 1.752 veículos sem rastreador, que juntos somam um 
montante de mais de US\$17,5 milhões, ou 70 mil salários mínimos ${ }^{10}$. Os carros recuperados se tornam propriedade da seguradora, depois desta pagar a indenização para o segurado. A companhia, por sua vez, irá vender esses carros em leilão e, em menor quantidade, desmontá-los em desmanches próprios. Segundo a equipe, 2018 estava sendo um ano "fraco", pois poucos sinistros estavam ocorrendo. Ou seja, o desaquecimento do mercado de roubo de veículos neste período estava afetando as atividades e, inclusive, a expansão do setor de rastreamento e monitoramento de veículos da seguradora. Um CEO com visão de mercado, portanto, deveria regular as taxas de roubo e furto, bem como as de recuperação, mas não deveria tentar impedir que Grandão trabalhe.

\section{O SEGURO COMO MEDIADOR}

O seguro possui um caráter mediador de diferentes dimensões, todas centrais à governança do mercado de veículos roubados e seus atores de regulação. Enquanto uma tecnologia de reparação e indenização de danos ${ }^{11}$, o seguro é composto por um conjunto de técnicas e um esquema de racionalidade, que permite que um carro roubado se transforme em um carro legalizado (mediação ilegal-legal); que o proprietário sinta segurança ao dirigir e estacionar seu veículo (mediação seguro-segurança). Através da reparação da perda, pela indenização paga pela seguradora, a pessoa proprietária pode comprar um carro novo, ou mais novo. O mercado ilegal, através da mediação do seguro, fomenta assim a indústria legal de automóveis. Por sua vez, nas práticas cotidianas de Douglas, bem como da equipe de rastreamento e monitoramento, o seguro ocupa uma posição liminar entre segurança pública e privada e, como veremos, entre polícia e mundo do crime, política e mercados.

Esse esquema de racionalidade, que se torna visão de mundo, nos leva ao nosso segundo argumento, que tem como foco a relação das companhias seguradoras com os governos e com

10 Importante ressaltar que esse cálculo é feito pela própria equipe de recuperação através da somatória do preço de cada carro recuperado, segundo a tabela FIPE. Fora os custos de operação, a seguradora também não consegue revender os veículos pelo preço da tabela FIPE (pago na indenização). Em geral, os carros são vendidos em leilão por um valor abaixo da FIPE.

11 " $[. .$.$] insurance is a technique of reparation and indemnification of damages. It is a mode of administering$ justice which competes with that of legal right. It maintains a type of justice under which the damage suffered by one is borne by all, and individual responsibility is made collective and social. Whereas the principle of right concentrated on preserving the 'natural' allocation of advantages and burdens, insurance conceives justice according to a conception of sharing for which it undertakes to fix equitable rules" (EWALD, 2017, grifo nosso) 
o Estado. Argumentamos que é sobretudo a partir das redes e estruturas das forças policiais de base, de nível de rua, que a atividade de recuperação de veículos das seguradoras se viabiliza. Demonstrando etnograficamente como as informações, os conhecimentos e as pessoas provenientes do aparato institucional público são centrais ao ramo de recuperação de veículos das seguradoras, discuto a relação entre seguro, segurança pública e privada, portanto com o núcleo das funções estatais modernas. Contemporaneamente, e no sul Global, essas relações não se dão no cotidiano de nossos operadores por parcerias formais e documentos oficiais, mas pela venda privada e ilegal de serviços por parte de agentes da ordem a agentes de mercado.

Douglas, nosso pronta-resposta, afirma que a Alvorada Seguros costuma fazer eventos em que os que motoqueiros que mais recuperam carros recebem prêmios, tal como um Iphone ou um notebook ${ }^{12}$. Segundo ele, os que mais conseguem recuperar são os que têm acesso a informações privilegiadas, em geral provenientes de informantes policiais. Contou um caso em que três carros foram roubados em uma avenida próxima ao aeroporto de Congonhas. Primeiro, uma mulher sozinha teve seu Toyota Corolla roubado por dois adolescentes. O Corolla foi utilizado para roubar outros dois veículos: um Ford Eco Sport e um GM Safira. Coincidentemente, todos os carros eram assegurados pela Alvorada Seguros. Nenhum dos veículos possuía rastreador.

A informação veio para a Central através de um caçador, antes mesmo da companhia ser informada pelos segurados da ocorrência dos sinistros. O caçador conseguiu essa informação, antes mesmo da seguradora, porque tinha contatos privilegiados com policiais. As vítimas acionaram a polícia após os assaltos à mão armada, através do 190. O policial imediatamente informou seu amigo caçador. Esta é uma prática recorrente, que a depender do acordo, implica divisão informal do pagamento das seguradoras entre caçadores e policiais.

Por sua vez, em conversas privadas com gerentes e coordenadores da Central de recuperação de veículos, nos foi enfatizado que eles evitam contratar ex-policiais como caçadores, ou negociar a recuperação de um carro diretamente com a polícia, para proteger a imagem da companhia frente a possíveis escândalos de corrupção policial. A imagem da companhia deve ser zelada entre seus diretores e executivos, mas ninguém sabe quem são os operadores de base, que possuem os necessários vínculos com bandidos e policiais, como Douglas e seus colegas caçadores, e que, portanto, conseguem prestar um serviço mais eficiente à Alvorada. A seguradora possui este grupo de motoqueiros recuperadores, que atuam diariamente, apenas em São

12 O HB20 de João, recuperado por Douglas, rendeu 32 SM à Alvorada, e ele recupera em média 15 veículos por mês, na ordem de grandeza de 300 SM. Um Iphone como os sorteados, no Brasil, custa em torno de 5 SM. 
Paulo. Ocorrências de roubo e furto de outras cidades também são comunicadas à Central, mas a recuperação ali ocorre a partir da contratação de empresas terceirizadas. Quem são, em geral, os proprietários dessas empresas? Ex-policiais civis ou militares, em geral aposentados entre 45 e 60 anos, controlam esse novo negócio, assim como outros ramos da segurança privada no Brasil. Daí brota uma das bases materiais do protagonismo político que, na última década, as polícias vêm desempenhando no Brasil.

As situações descritas por Douglas e pelos interlocutores da Central de Monitoramento da Alvorada nos permitem sugerir, em diálogo com a teoria dos seguros, a ideia de uma "terceirização" das funções estatais de proteção, tocadas agora por agentes de mercado, e agentes dos mercados informais. Trata-se, aqui, de uma versão privatizada das "mercadorias políticas" descritas por Michel Misse (2018), que permitem "a conversão da ilegalidade em acumulação mercantil”" (MISSE, 2006). Pois por lei, seria de responsabilidade estatal garantir a segurança pública e recuperar os veículos roubados. Na prática, como vimos, as seguradoras assumem essas funções, delegando ao Estado a tarefa de punir, prender e, no limite, matar. Se ao longo de todo o livro veremos que a violência se concentra entre os grupos subalternos, na relação entre seguradoras e governantes, são os executivos do mercado os que têm as mãos mais limpas. É a partir dessa expropriação de funções estatais de proteção, sempre justificada pela ineficiência pública, circularmente comprovada em pesquisa de campo, que se fortalece o papel do seguro enquanto uma tecnologia pragmática de governo do conflito urbano. Técnicas e tecnologia a serviço de uma racionalidade, centrada em cálculos atuariais e gestão de risco no nível das populações, conhecimentos sobre prevenção e monitoramento, compõem essas formas de governo dos mercados, sobretudo do mercado de segurança, absolutamente relevante também ao governo dos distintos governos, ou à governança urbana, cada vez mais central às cidades contemporâneas (LE GALES; COURMONT, 2019).

Entrevistamos Castro, um ex-policial civil de São Paulo que, há 30 anos, atua na recuperação de veículos e de cargas em várias cidades do país. Nesta oportunidade, sugerimos almoçar em uma padaria. Castro se recusou e fez questão de nos levar para almoçar em um pequeno restaurante situado na frente da delegacia em que seu filho trabalha. Castro estacionou seu carro no terreno da delegacia, cumprimentou seus colegas policiais em serviço e nos contou, em um tom levemente ameaçador, que ali funcionou um braço do antigo DOPS. No restaurante, frequentado quase exclusivamente por policiais civis, ele já era conhecido e cumprimentava a todos com piadas em alto e bom som. Enquanto almoçávamos, Castro simultaneamente perguntava o que queríamos saber sobre sua atividade e desconversava. Não respondia nossas perguntas e falava aleatoriamente de assuntos banais. 
No entanto, em dado momento, de maneira aberta e objetiva, ele nos explicou que sua empresa paga policiais para recuperar carros roubados. No Rio de Janeiro, por exemplo, os policiais são pagos para recuperar os carros que estão dentro de favelas. O valor pago varia de acordo com a periculosidade do território, ou seja, onde o crime é mais forte e a polícia tem menos poder de circulação, custa mais caro. Castro faz seus negócios a partir de suas redes pessoais de confiança, mas sabe que quando o assunto é dinheiro, precisa pagar o quanto antes e cumprir o combinado com urgência. Caso contrário, sua vida pode correr risco.

Seu sócio e ex-tenente do Exército Brasileiro, Fernandez, nos explicou melhor sobre os trabalhos que realizam juntos. Segundo ele, Castro sempre atuou no ramo, mas não tinha uma empresa formal: “esse pessoal é tudo em dinheiro, né?! Ganhou 10 mil, 1 mil vai pra cá, 2 mil para lá. A Tróia é uma tentativa de criar uma empresa, é muito recente, está começando a operar". Da sua perspectiva, a sociedade parecia muito promissora. O Castro tem a experiência da rua e os contatos com os policiais. Enquanto que o Fernandez traria a "visão do empresário" e focaria na gestão do negócio: "Eu digo para o Castro que ele não tem mais que ficar na rua. Ele tem que fazer a política. Ir jantar com um delegado, conversar com um deputado sobre uma lei que precisa fazer e como tem que ser".

Fernandez explica que só contratam policiais, e sempre policiais fora de serviço. Disse não poder colocar uma pessoa sem o devido treinamento para recuperar um carro que está "descansando": "O policial já sabe. Ele passa aqui, fotografa os carros e manda pra gente. A gente confere e, se for o carro, ele volta senta em um café e fica vigiando o carro(...). Se o cara já chega e mete a mão na porta para abrir, já deixou a digital dele lá".

Sobre a remuneração em São Paulo, diz terem um valor fixo de 0,35 SM, de 50\% a 100\% a mais do que Douglas recebe da Alvorada Seguros. Fernandez explica que a remuneração que a sua empresa Tróia paga aos policiais. "tem que ser fixa, porque senão cria um mercado para os policiais". Quem são os principais clientes da empresa de Fernandez e Castro? As seguradoras, claro. As companhias contratam os serviços da Tróia para a recuperação de cargas e carros roubados assegurados. Fernandez enfatiza que não dá para as seguradoras se envolverem até o trabalho de base de recuperação.

Segundo ele, e esse é o ponto mais crucial de todos os mecanismos de reprodução das desigualdades urbanas, nesses mercados, "qualquer problema, elas [as seguradoras] podem alegar que não contrataram um policial, mas sim um outro CNPJ que contratou policiais". Na visão de um empresário brasileiro dos mercados de proteção, está claro que eles funcionam como uma das esferas, concebidas como autônomas, na cadeia que faz das seguradoras entidades totalmente legalizadas, e da "rua" o espaço das ilegalidades. Situadas nesse in between, as em- 
presas do ramo permitem que as seguradoras aleguem que "não sabiam de nada" do que ocorre nas negociações de base, entre policiais e seus agentes: "elas sabem, mas fazem vista grossa".

\section{REFERÊNCIAS}

1. AMIT, V.; KNOWLES, C. Improvising and Navigating Mobilities: Tacking in Everyday Life. Theory, Culture and Society, 2017. Disponível em: https://journals. sagepub. com/doi/10.1177/0263276417724876. Acesso em: 16 fev. 2020.

2. APPADURAI, A. The social life of things. New York: Cambridge University Press, 1986.

3. APPADURAI, A. Soberania sem territorialidade: notas para uma geografia pós-nacional. Revista Novos Estudos CEBRAP, n. 49, p. 33-46, 1997.

4. ARENDT, H. Rahel Varnhagen: a vida de uma judia alemã na época do Romantismo. Rio de Janeiro: Relume-Dumará, 1994.

5. BERTAUX, D. Biography and Society: The life history approach in the social sciences. Beverly Hills: SAGE Publications, 1981.

6. BIONDI, K. Proibido roubar na quebrada: território, hierarquia e lei no PCC. São Paulo: Terceiro Nome, 2018.

7. BOURDIEU, P. L'illusion biographique. Actes de la Recherche en Sciences Sociales, n. 62, p. 69-72, 1986. Disponível em: https://www.persee.fr/doc/arss_0335-5322_1986_ num_62_1_2317. Acesso em: 16 fev. 2020.

8. BOURDIEU, P. Esquisse pour une auto-analyse. Paris: Raisons d'Agir Éditions, 2004.

9. BOURDIEU, P. A Distinção - Crítica Social do Julgamento. 2. ed. Porto Alegre: Zouk, 2011.

10. CABANES, R. Travail et travailleurs de São Paulo, le réel biographique aux prises avex l'imaginaire mondialisé. Dans Travailler, n. 12, p. 67-90, 2004. Disponível em: https:// www.cairn.info/revue-travailler-2004-2-page-67.htm?contenu=resume. Acesso em: 15 fev. 2020.

11. CEFAÏ, D.; GARDELLA, E. L'Urgence sociale en action. Ethnographie du Samusocial de Paris. Paris: La Découverte., 2011.

12. DAS, V. Life and Words: Violence and the Descent into the Ordinary. Berkeley, CA: University of California Press, 2006.

13. FELTRAN, G. D. S. A categoria como intervalo: a diferença como essência e construção. 
Cadernos Pagu, n. 51, 2017. Disponível em: https://www.scielo.br/pdf/cpa/n51/18094449-cpa-18094449201700510005.pdf. Acesso: 15 fev. 2020.

14. FELTRAN, G. D. S. Governo que produz crime, crime que produz governo: o dispositivo de gestão do homicídio em São Paulo (1992 - 2012). Revista brasileira de segurança pública, v. 6, n. 2, p. 232-255, 2012. Disponível em: http://revista.forum seguranca.org. br/index.php/rbsp/article/view/118. Acesso em: 15 fev. 2020.

15. FELTRAN, Gabriel Santis. Irmãos: uma história do PCC. São Paulo: Companhia das Letras, 2018.

16. FELTRAN, G. D. S. The ordinary war: Ethnographic notes of urban conflict in São Paulo (Brazil). Homme, v. 219-220, n. 3-4, p. 93-113, 2016. Disponível: https://www .cairn-int.info/journal-1-homme-2016-3-page-93.htm. Acesso em: 16 fev. 2020.

17. FOUCAULT, M.; BARBIN, H. Herculine Barbin: being the recently discovered memoirs of a nineteenth-century French hermaphrodite. New York: Pantheon Books, 1980.

18. FREIRE-MEDEIROS, B.; MENEZES, P. V. As viagens da favela e a vida social dos suvenires. Sociedade e estado, v. 31, n. 3, p. 651-670, 2016. Disponível em: https:// www.scielo.br/pdf/se/v31n3/0102-6992-se-31-03-00651.pdf. Acesso em: 15 fev. 2020.

19. FREIRE-MEDEIROS, B.; TELLES, V. DA S.; ALLIS, T. Por uma teoria social on the move. Tempo Social, v. 30, p. 1-16, 2018. Disponível em: https://www.revistas.usp.br/ ts/article/view/142654. Acesso em: 19 fev. 2020.

20. GOFFMAN, E. Frame Analysis: An Essay on the Organization of Experience. Boston: Northeastern University Press, 2016.

21. HENARE, A.; HOLBRAAD, M.; WASTELL, S. Introduction: Thinking through things. In: HENARE, A.; HOLBRAAD, M.; WASTELL, S. Thinking Through Things: Theorising Artefacts Ethnographically. Londres: Routledge, 2006, p. 1-31.

22. HIRATA, D. V. Sobreviver na adversidade: entre o mercado e a vida. 2010. Tese (Doutorado em Sociologia) - Faculdade de Filosofia, Letras e Ciências Humanas, Universidade de São Paulo, São Paulo.

23. KNOWLES, C. Flip-Flop: A Journey Through Globalisation's Backroads. London: Pluto Press, 2014.

24. KOPYTOFF, I. The Cultural Biografy of Things: Comoditization as Process. In: APPADURAI, Arjun. The Social Life of Things. Cambridge: Cambridge University Press, 2014. p. 63-91.

25. LATOUR, B. Reassembling the Social: An Introduction to Actor-Network-Theory. Oxford: University Press, 2005.

26. LE GALES, P.; COURMONT, A. Gouverner la ville numérique. Paris: Presses 
Universitaires de France, 2019.

27. LEHTONEN, T.; VAN HOYWEGHEN, I. Editorial: Insurance and the economization of uncertainty. Journal of Cultural Economy, v. 7, n. 4, p. 532-540, 2014. Disponível em: https://www.tandfonline.com/doi/abs/10.1080/17530350.2013.87592 9. Acesso em: 17 fev. 2020.

28. LEWIS, O. The Children of Sanches, autobiography of a Mexican Family. New York: Random House, 1961.

29. MARTINS JR, A. Lives in Motion: Notebooks of an immigrant in London. London: Whyte Tracks, 2015.

30. MILLER, D. Car Cultures. Londres: Bloomsbury UK Academic, 2001.

31. MILLER, D. Stuff. Cambridge: Polity Press, 2010.

32. MINTZ, S. O poder amargo do açúcar: produtores escravizados, consumidores proletarizados. Recife: Editora UFPE, 2003.

33. MISSE, M. Violence, Criminal Subjection and Political Merchandise in Brazil: An Overview from Rio. International Journal of Criminology and Sociology, v. 7, p. 135-148, 2018. Disponível em: https://www.researchgate.net/publication/324453803 Violence_Criminal_Subjection_and_Political_Merchandise_in_Brazil_An_Overview_ from_Rio. Acesso em: 17 fev. 2020.

34. MISSE, M. Crime e Violência no Brasil Contemporâneo: Estudos de sociologia do crime e da violência urbana. Rio de Janeiro, Lumen Juris, 2006.

35. SIMMEL, G. The View of Life: Four metaphysical essays with Journal Aphorisms. Chicago: The University of Chicago Press, 2010.

36. TELLES, V. DA S. A cidade nas fronteiras do legal e ilegal. São Paulo: Argumentum, 2010.

37. TSINmG, A. L. Friction: An Ethnography of Global Connection. Princeton/Oxford: Princeton University Press, 2005.

38. URRY, J. Mobility and Proximity. Sociology, v. 36, n. 2, p. 255-274, 2002. Disponível em: https://journals.sagepub.com/doi/abs/10.1177/0038038502036002002. Acesso em: 17 fev. 2020

39. URRY, J. The "System" of Automobility. Theory, Culture \& Society, v. 21, n. 4/5, p. 25-39, 2004. Disponível em: https://www.researchgate.net/publication/258192332 The_'System'_of_Automobility. Acesso em: 17 fev. 2020.

40. URRY, J. Mobile Sociology. British Journal of Sociology, v. 61, p. 347-366, 2010. Disponível em: https://onlinelibrary.wiley.com/doi/full/10.1111/j.14684446.2009.01249.x. Acesso em: 14 fev. 2020. 
41. ZELIZER, Viviana A. Rotman. Morals and markets: The development of life insurance in the United States. Columbia University Press, 2017.

\section{Gabriel Feltran}

Professor do Departamento de Sociologia e Coordenador do Programa de Pós-Graduação em Sociologia da Universidade Federal de São Carlos. Doutor em Ciências Sociais pela Universidade Estadual de Campinas. ID ORCID: https://orcid.org/0000-0003-3424-0822. E-mail: gabrielfeltran@gmail.com. Colaboração: Pesquisa bibliográfica, Pesquisa empírica, Análise de dados, Redação.

\section{Deborah Fromm}

Doutoranda na Universidade Estadual de Campinas com Doutorado-sanduíche na Goldsmiths College, University of London. Mestre em Antropologia Social pela Universidade Estadual de Campinas. Bacharelado em Ciências Sociais pela Universidade Federal de São Carlos. Pesquisadora do Núcleo de Etnografias Urbanas (NEU/Cebrap). ID ORCID: https://orcid. org/0000-0002-1152-8877. E-mail: deborahrfromm@gmail.com. Colaboração: Pesquisa bibliográfica, Pesquisa empírica, Análise de dados, Redação. 